\title{
Generalized fire response strategies in plants and animals
}

\author{
Juli G. Pausas \\ CIDE-CSIC, Ctra. Naquera Km. 4.5, 46113 Montcada, Valencia, Spain, Phone: +34 963 \\ 424124 Email: juli.g.pausas@ext.uv.es, Web: https://www.uv.es/jgpausas/
}

Running title: Fire strategies in plants and animals

\begin{abstract}
Despite the existing large body of research on plant-animal interactions, plant research and animal research are still relatively independent and asymmetrical in relation to disturbance. Animals and plants are likely to have different fire responses, yet biodiversity studies in relation to disturbance may benefit from a more integrated functional approach across kingdoms. This would also force us to go deeper into the biological mechanisms and scales for persistence than a taxonomic-based classification. An integrated view of plant and animal responses would enable us to learn from a great variety of life forms and benefit from expertise in complementary disciplines. To achieve this integrated view, I propose a functional classification for both plants and animals in relation to their fire response strategy. This classification includes the following strategies: resistance, refugia, avoidance, dormancy, recolonization, crypsis, and intolerance. Given the limited knowledge of fire responses for many organisms, and especially for many animals, this classification may require further development. However, it provides a framework that facilitates finding knowledge gaps and directing future research for gaining a better understanding of the role of fire on biodiversity.
\end{abstract}

Keywords: fire ecology, fire responses, fire-prone ecosystems, fire strategies, functional types

The final version of this article will be published in Oikos (2019): https://doi.org/10.1111/oik.05907

\section{Introduction}

One of the objectives of ecology is to search for generalized patterns across systems and taxa. Despite the large body of research on plant-animal interactions, plant research and animal research are still relatively independent in relation to disturbance (McAlpine et al. 2016, Kelly et al. 2018). I propose that understanding the role of disturbance on biodiversity could benefit from a more integrated functional approach between plants and animals. This is especially relevant in the era of fire regime changes, as large and multidisciplinary sampling schemes are currently undertaken for understanding biodiversity changes (Kelly et al. 2017). Given that a functional classification must be taxa-independent, I ask: to what extent there is a unified functional classification of plants and animals in relation to fire?

There is a relatively ample knowledge regarding plant responses to fire (Bond \& van Wilgen 1996, Keeley et al. 2012). Functional classifications of plants in relation to fire are well established (Noble \& Slatyer 1980, Keeley \& Zedler 1998, Pausas et al. 2004, Keeley et al. 2012). This enables us to search for general and global ecological patterns (Pausas 2015a) as well as understanding the evolutionary history of fire traits in plants (Keeley et al. 2011, He et al. 2012, Charles-Dominique et al. 2015). In contrast, generalization on fire response for 
animals is still poor (Whelan 1995, Whelan et al. 2002, New 2014), although some patterns are emerging (e.g., van Mantgen et al. 2015). Moreover, the evolutionary role of fire for animals is still overlooked (Pausas \& Parr 2018) given the abundant fauna in fire-prone ecosystems (e.g., savannas). This asymmetry can be explained by the intrinsic differences in mobility and modularity. Plants are rooted (i.e., immobile) and modular; they cannot escape from fire but can survive if fire reduces the number of modules (leaves, branches, etc.). This has allowed the evolution of structural traits for the survival of plants (e.g., resprouting and thick barks) or seeds (e.g., serotiny and seed dormancy) and thus for the persistence of population (endogenous persistence; Keeley et al. 2012). Most animals are mobile and unitary organisms; survival is affected even if they are just partially burnt. Consequently, many traits related to animal survival may be behavioral (e.g., escape behavior) and thus more difficult to study (Pausas \& Parr 2018). Given that many animals have evolved in the presence of fire they may have developed coping strategies. As in plants, this does not mean that they may survive any fire (Keeley et al. 2011); changes in fire regime may also threaten animal populations even in fire-prone ecosystems.

Despite the differences between animals and plants, I would like to emphasize some of the similarities in relation to the mechanisms for living in fire-prone ecosystems. For instance, both seeds and larvae are life stages that may remain in the soil protected from the heat of the fire, and thus enable persistence of the population after fire. A high dispersal ability may confer the capacity for rapid postfire colonization in both plants and animals. The advantage of having a unified framework of fire strategies include: (1) we can learn how species respond to fire from a great diversity of life forms; (2) animal and plant ecologists can benefit from shared expertise in fire responses (some common strategies in plants may be overlooked in animals, or viceversa); (3) we could better predict changes in plant-animal interactions with fire regime changes, and (4) we could better assess and generalize the effects of fire on biodiversity.

There are many studies on the ecological responses of plants and animals to fire, including postfire successional studies and studies of communities under different fire regimes. They depict a reorganization of communities in response to fire, with positive and negative responses, depending on the species and fire characteristics. My aim is not to summarize temporal responses to fire, but to highlight the strategies for persisting in fire-prone environments. In their study on fauna responses to fire in the Californian chaparral, van Mantgem et al. (2015) provide an initial attempt to link plant and animal responses. Here I aim to generalize plant and animal fire response strategies in a single common framework that applies across fire-prone ecosystems worldwide. By fire response strategies I mean the mechanisms that the species use to persist in fire-prone ecosystems; the specific traits are likely to differ between animals and plants. Specifically, I propose six strategies (Table 1), plus an additional strategy for fire intolerant species (the lack fire persistence traits). The six strategies are combinations of traits for survival during fire, for survival immediately after fire, and/or for postfire recovery, and they are linked to persistence at different scales (Table 1). That is, these are adaptive strategies because they confer fitness benefits in fire-prone ecosystems (survival, and reproduction); they are not necessary fire adaptations in the sense that their origin may not always be exclusively linked to fire (see Keeley et al. 2011 for discussion in this topic). While evidences of fire adaptations in plants are common (Keeley et al. 2011, 2012, He et al. 2012, He \& Lamont 2018), the research on fire adaptation in animals is slowly growing (for a review, see Pausas \& Parr 2018). 
The proposed strategies occur in both plants and animals, although they act with different traits and mechanism, and they show differing prevalence (Table 1). Although all animals at the individual level may be considered 'intolerant to fire', here I refer to the dynamics of the population (Table 1); many animal populations survive and reproduce in fire-prone landscapes and have strategies to tolerate fire. Some of these strategies may be further subdivided, but for simplicity and generality, I will keep the number of strategies to a minimum. Below I briefly describe each strategy and provide some potential examples; I also highlight gaps in the knowledge on functional responses to fire.

\section{Fire response strategies}

Resistance - This category describes strategies that plants and animals have for surviving fire when being within the flame zone. Some species have traits that protect their most important tissues from the heat of the fire. This is very common in plants, where many species that get burnt, protect their buds underground (Pausas et al. 2018a), behind a thick bark (Pausas 2015a), or sunken in the trunk (Burrows 2002, Pausas \& Keeley 2017). There are probably no animals that have a comparable resistance to fire, but it is possible that some animals have traits that confer them some fire resistance and survival, at least to a low intensity fires. To what extent the abundance of terrestrial tortoise in some fire-prone ecosystems (Ernst et al. 1995; SanzAguilar et al. 2011) or the high fire resilience of snails (Kiss \& Magnin 2006) could respond to their protective shell remains to be studied. Some ectotherms have a physiological protection against high temperatures (a high upper critical thermal limit; Cerdà et al. 1998, ClusellaTrullas \& Chown 2014) that may contribute to their fire and postfire survival.

Refugia - Some species are located within (or move to) fire-protected microhabitats. For instance, in fire-prone landscapes, fire sensitive plant species only occur in gullies or rainforest pockets (Woinarski et al. 2004), or in outcrops (Clarke 2002), or any microsite that is unlikely to be affected by fire. Refugia is considered one of the fire strategies in pines (Keeley 2012); these species colonise from refugia during the fire-free interval. In the long-term, refugia populations may differentiate phenotypically (Leonard et al. 2018) suggesting long-term evolutionary consequences. In animals, many move to tree hollows, burrows, or other safe sites during the fire (Robinson et al. 2013). In fact, burrowing animal species tend to be abundant during early succession, compared with leaf-litter dwellers, because of their fire survival (Smith et al. 2013). Refugia can also be important in postfire conditions as provides shelter against predation (Leahy et al. 2016). Very often, only a subset of the individuals survive and persist (those that reach the safe site). If a fire return interval is long enough, there may be a nucleated recovery of the population from the safe sites. Some insects search protection within plants (Xanthorrhoea; Brennan et al. 2010), and many wingless insects (or wingless stages) move up trees during understory fires (Dell et al. 2017). Many of these animals are likely to have the ability to sense the fire in advance (from the smoke or sound; Schutz et al. 1999), although little research is available in this regard (Dell et al. 2017). This strategy should be prevalent under conditions that generate patchy burns at the scale of the given species (e.g., smaller in mollusks, Gaines et al. 2011; larger in vertebrates, Whelan et al. 2002). Species that follow this strategy have an endogenous dynamic as the local population is not extinguished after fire (the recovery is from the same gene pool), in contrast to the species with a exogenous recolonization strategy (see below). 
Avoidance - Some species avoid getting burnt by reducing flammability or locating important parts outside the flame zone. In contrast to Refugia, this strategy does not involve moving to a different habitat. Some plants can survive in frequently burnt ecosystems by evolving a very low flammability structure that confers survival (the non-flammable strategy; Pausas et al. 2017). This are plants that rarely burn despite living in ecosystems with surface fire regimes, like those shrubs that have very thick and sparse leaves and twigs, and trees that self-prune lower branches (i.e., the fire-tolerator syndrome in pines; Keeley \& Zedler 1998, Pausas $2015 \mathrm{~b}$ ); in both cases, the bark is relatively thick to survive surface fires. In the animal kingdom this strategy seems rare, and include species with a deliberate behavior for modifying their surrounding environment (niche construction), without having to move to a different location. For instance, there is evidence that some animals, including the Australian lyrebird (Nugent et al. 2014), the mallee fowl (Smith et al. 2017), and some Brazilian leaf-cutter ants (Carvalho et al. 2012), reduce litter around their nests to inhibit nearby surface fires ('fuel management'); these behaviors likely increase their fitness, although further research may be needed. This strategy is more prevalent in surface fire regimes, where fires are of low intensity.

Dormancy - Some species may not tolerate fire as adults, but resist fire in a dormant life stage - so enabling the persistence of populations. This is very common in plants (postfire seeders; Keeley et al. 2012) and often fire is required to break seed dormancy, and thus to complete their life cycle; no such strong fire-dependence is currently known in animals. In many cases, the population size of these plant species increases postfire because of the enhance germination in a rich environment with less competition and predation. Some animal populations persist after fire because the eggs or pupae are below ground during the fire season (Pausas et al. 2018b). As in plants, fire may act as a cue synchronizing the emergence of some insects in a favorable environment (Jacobs et al. 2011); to what extent this synchronization may favor them by satiating predators or by facilitating mutualistic interactions, remains to be studied. In plants, this strategy is linked to relatively high intensity fire regimes with fire intervals constrained by maturity age and longevity (Pausas \& Keeley 2014), but little is known about the optimal fire regime for animals. While the fire season may be of some importance in plants (Bond 1984), it may be more relevant in many animals as it requires a match with the dormant life stage.

Exogenous recolonization - Many species may not survive fire, but are present after a fire (in the first postfire year) thanks to a good dispersal and ability to quickly recolonize. These species show metapopulation dynamics, that is, the recolonization is from individuals from neighboring populations, in contrast with the refugia strategy where the postfire population is the same as (or a subset of) the prefire population; consequently, these two strategies have different genetic consequences. Population size may increase postfire because the conditions for these species have improved (e.g., open environments, fleshy vegetation, and less competition). In some cases, this may include a fast colonization of species that were almost absent, and are attracted by fire (e.g., some saproxylic insects, Evans 2010) or postfire conditions (e.g., opportunistic animals and plants). Typical examples of exogenous colonization are those plants under crown-fire regimes that lack adaptations to crown fires but have relatively good dispersal ability (Rodrigo et al. 2004, Owen et al. 2017). Generalist animals tend to recolonize faster than specialist animals as the latter may first require the regeneration of their host (Garcia et al. 2016). This strategy is more likely under regimes where fires are intense, homogeneous (refugia is unlikely), and large (in relation the home range of the species). 
Intolerance - Many species may be fire intolerant, that is, they cannot resist fire, nor can they regenerate (no population persistence) after fires. In addition, their dispersal ability is low and they may take a long time to recolonize (assuming they are found in neighboring areas). These species temporarily disappear from the burn area (local extinction), and do not occur in ecosystems with high fire recurrence; most do not actively use refuges. Intolerant species often refers to a given fire regime; however there are species sensitive to almost any fire, like many thin-barked rainforest trees (Dantas et al. 2013, Brando et al. 2014). Animals with limited movement ability and that accomplish their whole life cycle on plants, are likely to be intolerant to high intensity fires than consume their host plant, although the fire intolerance can also depend on the effect on other threats in the landscape (Lindenmayer et al. 2011). Examples of fire intolerant species are those that show a positive relation with time since fire; if fact, from a community perspective, these species are often considered late successional species or species typical of pyrophobic alternative stable states (Dantas et al. 2013). Intolerant species are more likely to be excluded under regimes of high intensity fires; they are also specially vulnerable to anthropogeneic increases of fire activity (e.g., Holz et al. 2014, Haverkamp et al. 2015).

Crypsis - Because postfire conditions are quite different from prefire conditions, some species may have an (additional) strategy to survive the postfire environment. This is especially relevant in animals that have a survival strategy (resistance, refugia, avoidance; Table 1) because their feeding and hiding capacity may change strongly after a fire (indirect fire effects; Whelan et al. 2002). Thus, some animals acquire additional strategies for surviving postfire environments, such as cryptic (dark) colors in adults (Guthrie 1967, Kiltie 1989, Lillywhite et al. 1977, Forsman et al. 2011), or in their chicks and eggs (ground-nesting birds; de Ronde et al. 2004); or the capacity to enter in torpor after fire (Stawski et al. 2015). In plants, this is very rare or overlooked, but some plants have darker seeds in postfire environments to reduce seed predation (Lev-Yadun \& Ne'eman 2013).

\section{Remarks}

Although many species may have one of these fire response strategies, other species may respond with different mechanisms after fire. For instance, a subset of the population may persist in refugia while others may disappear only to undertake a postfire colonization from neighboring populations (Puig-Gironès et al. 2018); this alternative response may depend on the fire characteristics (size, intensity, and patchiness) including the relation between fire seasonality and species phenology; a specific fire regime may select for the dominance of one of these strategies. This variability is probably more relevant in animals than in plants, because both refugia and recolonization strategies are more important in animals (Table 1). Many plants also show traits that confer different strategies; for instance, there are plants that reveal both resistance and dormancy strategies in such a way that after the fire they can resprout from vegetative buds - as well as recruiting from a seed bank (postfire facultative species; Keeley et al. 2012, Pausas \& Keeley 2014), and the relative importance of each strategy may vary among individuals and across the landscape. Different strategies (within a species) have different genetic consequences in both plants (Segarra-Moragues \& Ojeda 2010) and animals (Smith et al. 2014), and thus can be selected under given fire regimes. 
The unified framework also enables the differences between plants and animals to be seen. For instance, in plants, endogenous recovery (individual and population persistence) can be attained under any fire regime (see high prevalence in plants, Table 1), including under high intensity fire regimes (resistance, dormancy; Table 1); however, for animals, endogenous recovery is mainly expected in patchy burns (see high prevalence in animals, Table 1; see also van Mantgem et al. 2015). Colonization from neighboring populations (exogenous dynamics; Table 1) is much more relevant in animals than in plants. These differences in postfire colonization and dispersal could have the consequence of a higher gene flow in animals (less isolation) than in plants, and may help to explain the lower evolutionary role of fire in animals. Comparison of the generic structure of animal and plant populations within and between the same fire strategy (and with similar spatial scales) would provide clues about the relative evolutionary role of fire in these two clades.

The proposed strategies are considered adaptive in fire-prone ecosystems as they confer fitness benefits in those habitats. In plants there is evidences that many fire persistence traits originate as response to fire (fire adaptations; Keeley et al. 2011, 2012, He et al. 2011, He \& Lamont 2018). To what extent these strategies in animal originated as a direct response to fire, they were only fine-tuned by fire, or they just evolved independently of fire, is unknown but opens up a whole research agenda for understanding biodiversity in fire-prone ecosystems (Geiser et al. 2017, Pausas \& Parr 2018).

Although much work is still needed to generalize fire response strategies across kingdoms, I propose that studying the functional responses of animals and plants following a common functional classification may provide a better view of the persistence mechanisms of biodiversity than a taxonomic classification. This effort may also release our research from historical constraints and biases imposed by the different disciplines (McAlpine et al. 2016). One way to demonstrate the validity of this approach would be to show that the classification of strategies explain more variability in fire responses than spliting the biodiversity in taxonomic groups. Conservation and fire management strategies may also benefit from this framework as they typically focus on either plants or animals; the common strategies may help finding fire management options for a more holistic view of biodviersity.

The proposed functional classification may be refined as we learn more about fire responses across species. One improvement would be to better link the different strategies with fire regimes. For instance, both resprouting from basal buds and surviving thanks to thick bark provide the same function, i.e., individual plants survive fire (resistance, Table 1), but these two mechanisms have evolved in response to different fire regimes. Plants with a soil or with a canopy seed bank are both included in the dormancy strategy, but those with canopy seed banks are more sensitive to short-fire intervals (Pausas \& Keeley 2014). However, this type of knowledge is still poor for fauna. Promoting fires is an important factor for plants (increasing flammability; Pausas et al. 2017) and could be the basis of another strategy, but the evidence for animals promoting fires is currently anecdotal (Bonta et al. 2017). The other challenge is to fit species interactions in this framework; for instance, are all combinations of plant and animal strategies possible in fire-prone ecosystems? Are interacting plants and animals more likely to belong to the same fire response strategy? Can we predict the fate on an interaction postfire by 
knowing the fire strategy of each component? The generalized fire response strategies proposed here may provide a first step towards answering these questions.

\section{Acknowledgments}

This research was funded by the project FILAS (CGL2015-64086-P) from the Spanish Government (Ministerio de Economía y Competitividad) and the PROMETEO/2016/021 project from the Valencia government (Generalitat Valenciana, Spain). I thank X. Santos, J. Belliure, Y. García and A. Smith for helpful comments on an early version of this paper. CIDE (Desertification Research Center) is a joint institute of the Spanish National Research Council (CSIC), the University of Valencia, and Generalitat Valenciana. I declare no conflict of interest.

\section{References}

Bond, W. J. 1984. Fire survival of Cape Proteaceae: influence of fire season and seed predators. - Plant Ecol. 56: 65-74.

Bond, W. J., et al. 2012. Which trees dominate in savannas? The escape hypothesis and eucalypts in northern Australia. - Austral Ecol. 37: 678-685.

Bond, W. J. and Van Wilgen, B. W. 1996. Fire and Plants. - Chapman \& Hall.

Bonta, M., et al. 2017. Intentional fire-spreading by "firehawk" raptors in northern Australia. Journal of Ethnobiology 37: 700-718.

Brennan, K. E. C., et al. 2011. Fire refugia: The mechanism governing animal survivorship within a highly flammable plant. - Austral Ecol. 36: 131-141.

Burrows, G. E. 2002. Epicormic strand structure in Angophora, Eucalyptus and Lophostemon (Myrtaceae) - implications for fire resistance and recovery. - New Phytol. 153: 111-131.

Cerdà, X., et al. 1998. Critical thermal limits in Mediterranean ant species: trade-off between mortality risk and foraging performance. - Funct. Ecol. 12: 45-55.

Charles-Dominique, T., et al. 2015. Bud protection: a key trait for species sorting in a forestsavanna mosaic. - New Phytol. 207: 1052-1060.

Clarke, P. J. 2002. Habitat insularity and fire response traits: evidence from a sclerophyll archipelago. - Oecologia 132: 582-591.

Clusella-Trullas, S. and Chown, S. L. 2014. Lizard thermal trait variation at multiple scales: a review. - Journal of Comparative Physiology B 184: 5-21.

Dantas, V. L., et al. 2013. Fire drives functional thresholds on the savanna-forest transition. Ecology 94: 2454-2463.

De Ronde, C. J., et al. 2004. Fire effects on flora and fauna. - In: Goldammer, J. G. and De Ronde, C. J. (eds.), Wildlife fire management handbook for South Africa. Global Fire Monitoring Centre.

Dell, J., et al. 2017. An arthropod survival strategy in a frequently burned forest. - Ecology 98: 2972-2974.

Ernst, C., et al. 1995. Fire cology of the Florida box turtle, Terrapene carolina bauri. Herpetological Review 26: 185-186.

Evans, W. G. 2010. Reproductive role of infrared radiation sensors of Melanophila acuminata (Coleoptera: Buprestidae) at forest fires. - Ann. Entomol. Soc. Am. 103: 823-826.

Forsman, A., et al. 2011. Rapid evolution of fire melanism in replicated populations of pygmy grasshoppers. - Evolution 65: 2530-2540. 
Gaines, W. L., et al. 2011. Monitoring the short-term effects of prescribed fire on an endemic mollusk in the dry forests of the eastern Cascades, Washington, USA. - For. Ecol. Manage. 261: 1460-1465.

García, Y., et al. 2016. Fires can benefit plants by disrupting antagonistic interactions. Oecologia 182: 1165-1173.

Geiser, F., et al. 2017. Phoenix from the ashes: Fire, torpor, and the evolution of mammalian endothermy. - Frontiers in Physiology 8: 842.

Guthrie, R. D. 1967. Fire melanism among mammals. - Am. Midl. Nat. 77: 227-230.

Haverkamp, C., et al. 2015. Effect of landscape fires on the demography of the endangered New Caledonian conifer Callitris sulcata. - Biol. Conserv. 191: 130-138.

He, T., et al. 2012. Fire-adapted traits of Pinus arose in the fiery Cretaceous. - New Phytol. 194: 751-759.

He, T. and Lamont, B. B. 2018. Baptism by fire: the pivotal role of ancient conflagrations in evolution of the Earth's flora. - National Science Review 5: 237-254.

Holz, A., et al. 2015. Effects of high severity fire drove the population collapse of the subalpine Tasmanian endemic conifer Athrotaxis cupressoides. - Global Change Biol. 21: 445-458.

Jacobs, J. M., et al. 2011. Low intensity surface fire instigates movement by adults of Calosoma frigidum (Coleoptera, Carabidae). - ZooKeys: 641-649.

Keeley, J. E., et al. 2012. Fire in Mediterranean ecosystems: ecology, evolution and management. - Cambridge University Press.

Keeley, J. E., et al. 2011. Fire as an evolutionary pressure shaping plant traits. - Trends Plant Sci. 16: 406-411.

Keeley, J. E. and Zedler, P. H. 1998. Evolution of life histories in Pinus. - In: Richardson, D. M. (ed.) Ecology and biogeography of Pinus. Cambridge University Press, pp. 219-250.

Kelly, L. T., et al. 2017. Fire regimes and environmental gradients shape vertebrate and plant distributions in temperate eucalypt forests. - Ecosphere 8: e01781.

Kelly, L. T., et al. 2018. Bridging the divide: integrating animal and plant paradigms to secure the future of biodiversity in fire-prone ecosystems. - Fire 1: 29.

Kiltie, R. A. 1989. Wildfire and the evolution of dorsal melanism in fox squirrels, Sciurus niger. - J. Mammal. 70: 726-739.

Kiss, L. and Magnin, F. 2006. High resilience of Mediterranean land snail communities to wildfires. - Biodiversity \& Conservation 15: 2925-2944.

Leahy, L., et al. 2016. Amplified predation after fire suppresses rodent populations in Australia's tropical savannas. - Wildl. Res. 42: 705-716.

Lindenmayer, D. B., et al. 2011. Newly discovered landscape traps produce regime shifts in wet forests. - Proc. Natl. Acad. Sci. USA 108: 15887-15891.

Leonard, J., et al. 2018. Differences in germination response to smoke and temperature cues in 'pyrophyte' and 'pyrofuge' forms of Erica coccinea (Ericaceae). - Int. J. Wildland Fire, doi:10.1071/WF17161

Lev-Yadun, S. and Ne'eman, G. 2013. Bimodal colour pattern of individual Pinus halepensis Mill. seeds: a new type of crypsis. - Biol. J. Linn. Soc. 109: 271-278.

Lillywhite, H. B., et al. 1977. Color matching and perch selection by lizards in recently burned chaparral. - Copeia 1977: 115-121.

McAlpine, C., et al. 2016. Integrating plant- and animal-based perspectives for more effective restoration of biodiversity. - Front. Ecol. Environ. 14: 37-45.

New, T. R. 2014. Insects, Fire and Conservation. - Springer.

Noble, I. R. and Slatyer, R. O. 1980. The use of vital attributes to predict successional changes in plant communities subject to recurrent disturbances. - Vegetatio 43: 5-21. 
Nugent, D. T., et al. 2014. Interactions between the superb lyrebird (Menura novaehollandiae) and fire in south-eastern Australia. - Wild1. Res. 41: 203-211.

Owen, S. M., et al. 2017. Spatial patterns of ponderosa pine regeneration in high-severity burn patches. - For. Ecol. Manage. 405: 134-149.

Pausas, J. G. 2015a. Bark thickness and fire regime. - Funct. Ecol. 29: 315-327.

Pausas, J. G. 2015b. Evolutionary fire ecology: lessons learned from pines. - Trends Plant Sci. 20: $318-324$.

Pausas, J. G., et al. 2004. Plant functional traits in relation to fire in crown-fire ecosystems. Ecology 85: 1085-1100.

Pausas, J. G. and Keeley, J. E. 2014. Evolutionary ecology of resprouting and seeding in fireprone ecosystems. - New Phytol. 204: 55-65.

Pausas, J. G. and Keeley, J. E. 2017. Epicormic resprouting in fire-prone ecosystems. - Trends Plant Sci. 22: 1008-1015.

Pausas, J. G., et al. 2017. Flammability as an ecological and evolutionary driver. - J. Ecol. 105: 289-297.

Pausas, J. G., et al. 2018a. Unearthing belowground bud banks in fire-prone ecosystems. - New Phytol. 217: 1435-1448.

Pausas, J. G., et al. 2018b. Fire benefits flower beetles in a mediterranean ecosystem. - PLoS One 13: e0198951.

Pausas, J. G. and Parr, C. L. 2018. Towards an undertanding of the evolutionary role of fire in animals. - Evol. Ecol. 32: 113-125.

Puig-Gironès, R., et al. 2018. Importance of internal refuges and the external unburnt area in the recovery of rodent populations after wildfire. - Int. J. Wildland Fire 27: 425-436.

Robinson, N. M., et al. 2013. Refuges for fauna in fire-prone landscapes: their ecological function and importance. - J. Appl. Ecol. 50: 1321-1329.

Rodrigo, A., et al. 2004. Direct regeneration is not the only response of Mediterranean forests to large fires. - Ecology 85: 716-729.

Sanz-Aguilar, A., et al. 2011. Coexisting with fire: The case of the terrestrial tortoise Testudo graeca in mediterranean shrublands. - Biol. Conserv. 144: 1040-1049.

Schutz, S., et al. 1999. Insect antenna as a smoke detector. - Nature 398: 298-299.

Segarra-Moragues, J. G. and Ojeda, F. 2010. Post-fire response and genetic diversity in Erica coccinea: connecting population dynamics and diversification in a biodiversity hotspot. Evolution 64: 3511-3524.

Smith, A., et al. 2017. Less fuel for the fire: malleefowl (Leipoa ocellata) nesting activity affects fuel loads and fire behaviour. - Wildl. Res. 43: 640-648.

Smith, A. L., et al. 2013. Successional specialization in a reptile community cautions against widespread planned burning and complete fire suppression. - J. Appl. Ecol. 50: 1178-1186.

Smith, A. L., et al. 2014. Life history influences how fire affects genetic diversity in two lizard species. - Mol. Ecol. 23: 2428-2441.

Stawski, C., et al. 2015. The importance of mammalian torpor for survival in a post-fire landscape. - Biol. Lett. 11: 20150134.

van Mantgem, E. F., et al. 2015. Faunal responses to fire in chaparral and sage scrub in California, USA. - Fire Ecol. 11: 128-148.

Whelan, R. J. 1995. The Ecology of Fire. - Cambridge University Press.

Whelan, R. J., et al. 2002. Critical life cycles of plants and animals - developing a processbased understanding of population changes in fire-prone landscapes. - In: Bradstock, R., et al. (eds.), Flammable Australia. Cambridge University Press, pp. 94-124. 
Table 1. Generalized mechanisms of species response to fire (strategy), their fire dynamics and persistence scale, the prevalence for animals and plants in fire prone ecosystems (low, moderate, and high) and some traits related to strategy. The last column refers to the fire characteristics where this strategy is most likely to occur ('high' and 'low' refers to fire intensity; 'patchy' refers to high level of patchiness; 'seasonal' refers to strong seasonality; 'large' refers to the size of the area burnt); and more details can be found in the text. Individual persistence implies low postfire mortality while the other persistence scales implies high postfire mortality. Some examples of each strategy are provided in the text.

\begin{tabular}{|c|c|c|c|c|c|c|}
\hline Strategy & Dynamics & $\begin{array}{l}\text { Persistence } \\
\text { scale }\end{array}$ & Kingdom & Prevalence & Traits & $\begin{array}{l}\text { Fire } \\
\text { regime }\end{array}$ \\
\hline \multirow{2}{*}{ Resistance } & \multirow{2}{*}{$\begin{array}{l}\text { Fire } \\
\text { survival }\end{array}$} & \multirow{2}{*}{ Individual } & Plants & High & Resprouting, thick bark & Any \\
\hline & & & Animals & Low & $\begin{array}{l}\text { Thick cover, physiological } \\
\text { tolerance }\end{array}$ & Low \\
\hline \multirow{2}{*}{ Refugia } & \multirow{2}{*}{$\begin{array}{l}\text { Fire } \\
\text { survival }\end{array}$} & \multirow{2}{*}{ Individual } & Plants & Low & Lack of fire related traits & Patchy \\
\hline & & & Animals & High & $\begin{array}{l}\text { Fire detectors, ability to } \\
\text { quickly react (hide) }\end{array}$ & Patchy \\
\hline \multirow[t]{2}{*}{ Avoidance } & \multirow{2}{*}{$\begin{array}{l}\text { Fire } \\
\text { survival }\end{array}$} & \multirow[t]{2}{*}{ Individual } & Plants & Mod & $\begin{array}{l}\text { Low flammability, self- } \\
\text { pruning }\end{array}$ & Low \\
\hline & & & Animals & Low & $\begin{array}{l}\text { Behavioral traits to reduce } \\
\text { habitat flammability }\end{array}$ & Low \\
\hline \multirow{2}{*}{ Crypsis } & \multirow{2}{*}{$\begin{array}{l}\text { Postfire } \\
\text { survival }\end{array}$} & \multirow{2}{*}{ Individual } & Plants & Low & Cryptic seeds & \\
\hline & & & Animals & Mod & Cryptic body, torpor & \\
\hline \multirow{2}{*}{ Dormant } & \multirow{2}{*}{$\begin{array}{l}\text { Propagule } \\
\text { survival }\end{array}$} & \multirow{2}{*}{ Population } & Plants & High & Seed dormancy, serotiny & High \\
\hline & & & Animals & Low & $\begin{array}{l}\text { Underground life stages } \\
\text { during the fire season }\end{array}$ & Seasonal \\
\hline \multirow{2}{*}{$\begin{array}{l}\text { Exogenous } \\
\text { recolonizing }\end{array}$} & \multirow{2}{*}{$\begin{array}{l}\text { Postfire } \\
\text { dynamics }\end{array}$} & \multirow{2}{*}{ Landscape } & Plants & Low & High dispersal (wind) & High \\
\hline & & & Animals & High & $\begin{array}{l}\text { High mobility (large, with } \\
\text { wings) }\end{array}$ & High, large \\
\hline \multirow{2}{*}{ Intolerance } & \multirow{2}{*}{$\begin{array}{l}\text { Local } \\
\text { extinction }\end{array}$} & \multirow{2}{*}{ Region } & Plants & No & Lack of fire related traits & No \\
\hline & & & Animals & No & Lack of fire related traits & No \\
\hline
\end{tabular}

